degenerate. Relief of pain is more likely than restoration of movement. When it is the cause of the symptoms the evacuation of a localised calcified deposit of toothpaste-like material can be very rewarding. Complete acromionectomy prejudices the power of the deltoid muscle and partial excision is apt to fail to relieve the trouble. The whole glenohumeral joint can be lowered away from the acromion by glenoid osteotomy. ${ }^{6}$ In the past little attention has been paid to the acromioclavicular joint in the painful arc syndrome. It may be that, as is now suggested, ${ }^{4}$ excision of the outer centimetre of the clavicle should be more often considered when a resistant example of the syndrome is accompanied by degenerative changes in the acromioclavicular joint.

${ }^{1}$ Bulgen, D Y, Hazleman, B L, and Voak, D, Lancet, 1976, 1, 1042.

2 Macnab, I, Annals of the Royal College of Surgeons of England, 1973, 53, 271

${ }^{3}$ Blockey, N J, Wright, J K, and Kellgren, J H, British Medical fournal, $1954,1,1455$.

${ }^{4}$ Kessel, L, and Watson, M, fournal of Bone and foint Surgery, 1977, 59B, 166.

5 Neer, C S, fournal of Bone and foint Surgery, 1972, 54A, 41.

${ }^{6}$ Richards, D J, fournal of Bone and foint Surgery, 1969, 51 B, 179.

\section{Drinking behaviours}

\begin{abstract}
"In the tragic conflict between what he has been taught to desire and what he is allowed to get, a man has found in alcohol, as he has found in certain other drugs, a sinister but effective peacemaker, a means of securing for however short a time some way out of the prisonhouse of reality back to the Golden Age."
\end{abstract}

\section{WILFRED TROTTER, 1908}

In the tragedy of addiction the spotlight for too long has played on those who (in Britain at any rate) deserve to be billed only as bit-part actors-the junkies, the pot-smokers, and the pep-pill swillers. There has been a recent, welcome shift in the focus on to the near-forgotten victims of the real villain of the piece, the demon alcohol.

Alcoholism, or the "alcohol dependence syndrome," the term preferred in a recent WHO publication, ${ }^{1}$ is undoubtedly a main cause of both obvious and hidden physical and mental illness, of family disruption and social embarrassment, and a burden on the health services. What is new and deplorable is the rising scale of alcohol abuse among the young of both sexes and among women in general. In Britain alone there are estimated to be 300000 alcoholics. Their contribution to crime is enormous: there are as many as 75000 convictions for public drunkenness every year, and of those otherwise convicted between $40 \%$ and $60 \%$, have an alcohol problem. Alcohol disinhibits and releases aggression that can be directed outwards, leading to assaults on others, or directed inwards, resulting in suicidal attempts. Glatt ${ }^{2}$ found that at Warlingham Park Hospital nearly half the men alcoholics and more than one-third of the women conceded that when in drink they had behaved aggressively or had endangered themselves or others.

The crisis point for those who abuse alcohol is the loss of freedom of choice: the point, that is, when there is no option but to drink and to continue drinking, whether it be continuously, intermittently, or episodically. According to van Dijk ${ }^{3}$ alcoholism is a self-perpetuating disease and to explain his convincing thesis he has constructed a model of four interrelated vicious circles: the pharmacological, the cerebral, the psychological, and the social. Each circle reinforces the others, and the longer they continue to do so the more difficult does treatment become.

But in spite of the widespread prevalence of the alcohol dependence syndrome there is a correspondingly widespread conspiracy to conceal the victim-a conspiracy entered into by the alcoholic and his family for fear, no doubt, of public opprobrium. These attempts at concealment are themselves tragic because-contrary to general belief-the alcoholic can be helped substantially, and the sooner he seeks help the better. The average general practitioner is thought to be aware of only two or so of the 15 alcoholics in his practice. ${ }^{2}$ If he is to be, as he should be, the spearhead of the attack on alcoholism it is imperative that he should be constantly on the alert for its symptoms, often subtle and masked.

In this context a recent WHO publication ${ }^{1}$ is of particular importance. It describes some drinking behaviours (which in many ways complement van Dijk's vicious circles). Firstly, somatopathic drinking results in hangover or damage to tissues, such as gastritis, hepatitis, or myopathy. Second is thymogenic drinking, in which alcohol is essential in order to cope with the emotional problems of living. The third behaviour is dyssocial drinking leading to breaches of the criminal law, such as drunken driving; or to disruption of family or social relations; or to economic and occupational impairment. Lastly, there may be combinations of two behaviours, and any combination is strongly indicative of alcoholism, or at least of its prodromal stage. A combination of all three leaves no doubt that the worst has happened: a confident diagnosis of alcohol dependence syndrome may be made.

No one who drinks is above suspicion: the bell may toll for him.

1 Alcohol-Related Disabilities, eds G Edwards et al. Geneva, World Health Organisation, (offset publ No 32), 1977.

2 Glatt, M, The Alcoholic and the Help He Needs, 2nd edn. London, Priory Press, 1972

${ }^{3}$ van Dijk, W K, Medicine (London), 1975, No 13 pt 1, p 598.

\section{Relapse in leprosy}

Relapse in leprosy is no new thing. In the pre-sulphone era relapse after treatment with chaulmoogra oil or a derivative of hydnocarpic acid was the rule rather than the exception in cases of multibacillary leprosy. Hopes of permanent arrest of the disease were raised by the glowing reports when the sulphones ${ }^{1}$ were introduced in the early 1940s. Tuberculoid leprosy responded well, and relapse was uncommon when treatment was taken regularly and for long enough. In those days relapse was also rare in patients with lepromatous leprosy, but in patients suffering from intermediate types (borderline or dimorphous) the fairly rapid disappearance of skin lesions deluded clinicians into equating apparent clinical quiescence with cessation of mycobacterial multiplication: hence there was a high relapse rate in such cases in some series. $^{2}$

Today in well-supervised leprosy control programmes reactivation of the disease after insufficient treatment is less a cause for concern than is relapse that occurs despite adequate intake and absorption of an effective mycobacteriostatic drug, usually dapsone. ${ }^{3}$ The main reason for this increasingly disturbing trend is the emergence of dapsone-resistant leprosy 
organisms wherever the condition is recognised and the possibility of its existence entertained. First found in $1964,{ }^{4}$ dapsone-resistance has now been confirmed in the laboratory in most instances in which clinical suspicion and clinical confirmation have preceded mouse footpad inoculation by a technique developed by Rees. ${ }^{4}$

From recent experience, principally in Malaysia, ${ }^{5}$ Ethiopia, ${ }^{6}$ and the United States, it is now generally agreed, firstly, that treatment with dapsone alone is no longer permissible in patients with multibacillary leprosy; secondly, that each year dapsone resistance may be expected to emerge in about $3^{\circ}$ ", of patients with multibacillary leprosy who have been under treatment with dapsone alone for eight years or longer ${ }^{i}$; thirdly, that bacteriological reactivation usually precedes signs of clinical relapse ${ }^{*}$; and, finally, that wild strains of $M y c o-$ bacterium leprae will increasingly show varying degrees of dapsone resistance. ${ }^{9}$ The risk is enhanced by irregular intake of dapsone and probably also by very low-dose regimens and by the slow build-up of dapsone to the optimum level advocated in an attempt to minimise the risk of the dapsone-related reversal reaction with peripheral neuropathy. Since patient compliance in most leprosy treatment programmes is strongly suspected to be very low after the first few months (and may be tested by the presence or absence of sulphone in the urine $^{1011}$ ), the stage is sadly set for the emergence of dapsoneresistant bacilli on an unmanageable scale.

Secondary resistance (resistance developing during the course of treatment) may be recognised by the appearance of new skin lesions despite treatment, papular or diffuse erythematous rashes, and by the presence of solid-staining morphologically normal bacilli in smears and sections from the lesions themselves or from the nasal mucus. The new lesions are sometimes unfortunately misdiagnosed as manifestations of erythema nodosum leprosum and mistreated accordingly. Histopathologists will find much useful information in a recently published booklet. ${ }^{12}$

A more sinister condition that could masquerade as relapse is really a reinfection with dapsone-resistant bacilli. Primary dapsone resistance has now been found in lepromatous disease, ${ }^{9}$ thanks to an awareness of the possibility in one of the few existing centres of excellence and use of the mouse footpad inoculation technique. The epidemiological importance of this finding will not go unnoticed.

Early detection of relapse (or primary infection) due to dapsone-resistant organisms depends on awareness of the possibility and on recognition of the clinical and bacteriological accompaniments of the occurrence. This in turn presupposes higher standards of management of leprosy in all treatment programmes, an upgrading of training of auxiliary workers (including microscopists and laboratory technicians), and a reappraisal of the whole strategy of leprosy treatment and control programmes, whether integrated or not into the general health services.

As if the problems of relapse due to dapsone-resistant organisms were not enough, recent work suggests that some cases of relapse after a more or less prolonged period of clinical and bacteriological quiescence (during which an antileprotic drug may or may not have been taken) may be due to the reactivation of dormant dapsone-sensitive organisms, particularly in bone marrow and lymph nodes. Such organisms have been found after several years of treatment with dapsone or clofazimine and even after two years' treatment with rifampicin. ${ }^{13}$ The occurrence of this kind of relapse should be suspected when clinical signs of activity recur in patients who had suffered from a multibacillary form of leprosy before achieving quiescence. Morphologically normal solidstaining bacilli reappear in the dermis and nasal mucus, only to disappear when dapsone is given again.

So far, all patients suffering from relapse due to dapsoneresistant organisms have responded to either clofazimine or rifampicin. But since two cases of rifampicin-resistance have been reported ${ }^{14}$ it is now theoretically advisable to recommend treatment with both rifampicin and clofazimine for all such patients, with the aim of postponing indefinitely the emergence of organisms resistant to one or other of these valuable drugs.

Browne, S G, International fournal of Leprosy, 1965, 33, 273.

'Davey, T F, Transactions VIIth International Congress of Leprology, Tokyo 1958 , p 241

3 World Health Organisation Expert Committee on Leprosy, Fifth Report, Technical Report Series 607. Geneva, World Health Organisation, 1977.

Pettit, J H S, and Rees, R J W, Lancet, 1964, 2, 672

Pearson, J M H, Rees, R J W, and Waters, M F R, Lancet, 1975, 2, 69.

Waters, M F R, Leprosy Review, 1977, 48, 95.

Pearson, J M H, Ross, W F, and Rees, R J W, International fournal of Leprosy, 1976, 44, 140

* Browne, S G, Transactions St Fohn's Hospital Dermatological Society, 1973, 59, 225.

${ }^{9}$ Pearson, J M H, Haile, G S, and Rees, R J W, Leprosy Review, 1977, 48, 129.

1" Ellard, G A, Gammon, P T, and Harris, J M, Leprosy Review, 1974, 45, 224.

${ }^{11}$ Low, S J M, and Pearson, J M H, Leprosy Reviewi, 1974, 45, 218.

${ }^{12}$ Ridley, D S, Skin Biopsy in Leprosy. Basle, Ciba-Geigy, 1977.

${ }^{13}$ Rees, R J W, Leprosy Review, 1975, 46, suppl 2, 121.

${ }^{14}$ Jacobson, R R, and Hastings, R C, Lancet, 1976, 2, 1304.

\section{Bleeding in the newborn}

Haemostasis develops in an orderly way during intrauterine life. ${ }^{1}$ The most primitive reaction-contraction of the blood vessels in response to injury-is present from eight weeks, though its strength does not become normal until much later. Platelets appear in the circulation by 11 weeks and can form aggregates by 12-15 weeks; they approximate to adult numbers by 30 weeks. Clotting and fibrinolytic plasma proteins are found from 10-11 weeks; the concentrations of some clotting factors reach adult values in utero, but that of others-mainly those dependent on vitamin K (II, VII, IX, and X)-are still low at term. Susceptibility to haemorrhage is thus increased at low gestational age, and, as Bleyer and colleagues ${ }^{2}$ have pointed out, the preterm infant is born with fragile vessels, imperfect platelets, and reduced amounts of nearly all clotting factors. Indeed, the widespread bruising apparent in some tiny babies at birth underlines their vulnerability, and haemorrhage was listed as the primary cause of death in $5 \%$ and as the first secondary cause in $4 \%$ of singleton infants dying in the first week of life in the British Births survey of $1970 .^{3}$

Though the complexities of haemostasis may be almost as bewildering and frightening to the clinician as neonatal haemorrhage itself, the results of a careful clinical examination of the infant, a relatively few screening tests, and a detailed maternal and family history will usually lead to the diagnosis. ${ }^{3}$ Apart from estimation of the haemoglobin and scrutiny of the blood film, measuring the platelet count, prothrombin time, partial thromboplastin time, and the fibrinogen concentration are the most important investigations. The commercially available Thrombotest may also be useful: it measures simultaneously the combined effect of factor IX in the slower intrinsic clotting process and prothrombin and factors VII and $\mathrm{X}$ in the faster extrinsic clotting process. ${ }^{4}$

In vigorous, normally grown infants with no enlargement 